\title{
AN ANALYTICAL STUDY OF THE RELATIONSHIP BETWEEN SOME SOCIAL VARIABLES AND ENVIRONMENTAL PRACTICES:"A FIELD STUDY IN VILLAGE OF DAKAHLIA GOVERNORATE"
}

Attia, Amany A. N. E.

Dept. of Agric. Extension and Rural Sociology, Faculty of Agriculture, Mansoura University

لرراسة تحليلة للعلاقة بين بعض المتفيرات الاجتماعية وبين الممارسـات البيئية:

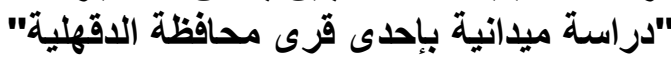
أماني أحمد نادر السيد عطيه قسم الإرشاد الزراعى والاجتماع الريفى ـ كلية الزراعة - جامعة المنصورة

\author{
الملخص
}

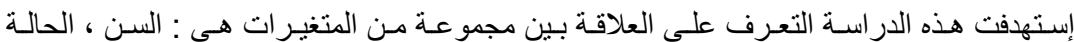

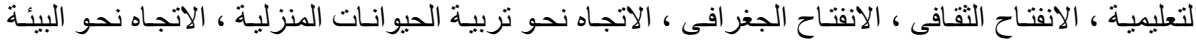

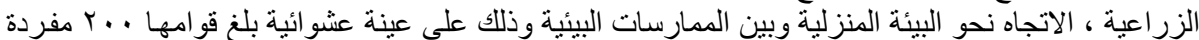

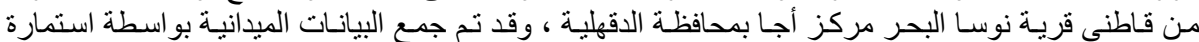

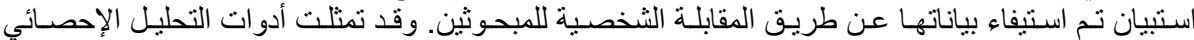

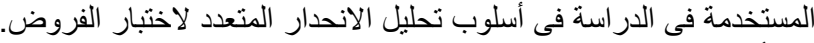

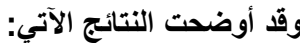
ا -وجود متغيرين أسهوفو أسيهاماً متميز أ فى تفسير التباين الكلى للممارسات الصحية و الغذائية وهذان المتغيران

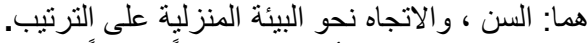

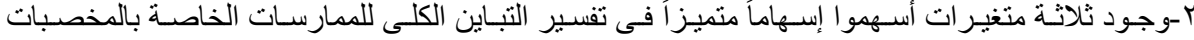

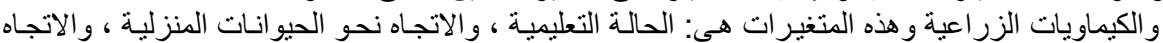
نحو البيئة المنزلية على الزئية الترتيب.

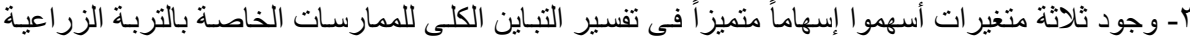

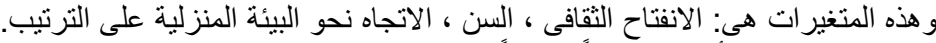

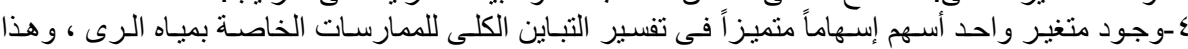
المتغير هو السن.

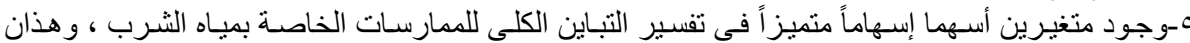

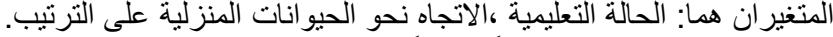

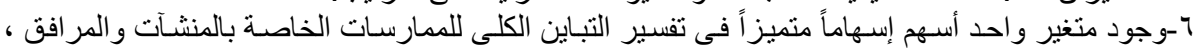

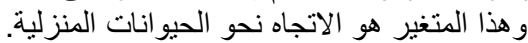

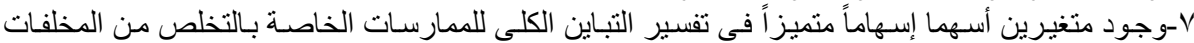

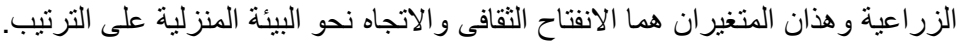

\section{المقدمة والمشكلة البحثية}

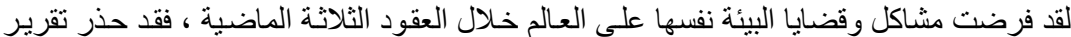

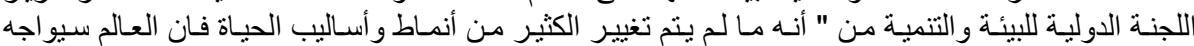

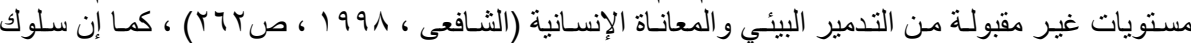

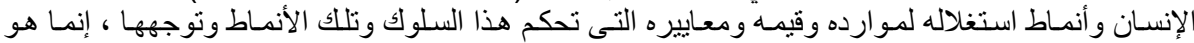

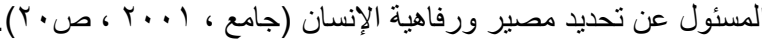

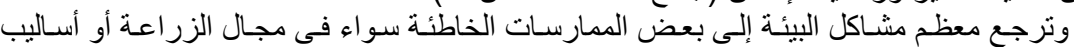

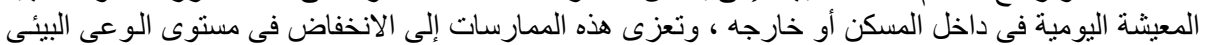


Attia, Amany A. N. E.

للأسرة الريفية وخاصةً المر أة لأنها المسئولة عن تكوين الأسرة وغرس القيم و والعادات و السلوكيات المتعلقة

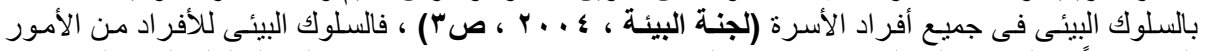

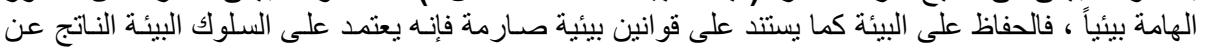

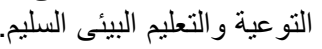

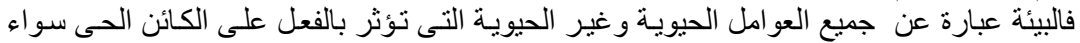

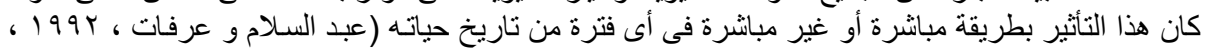

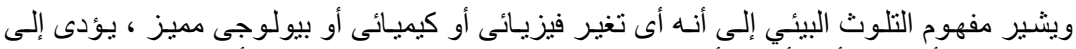

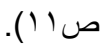

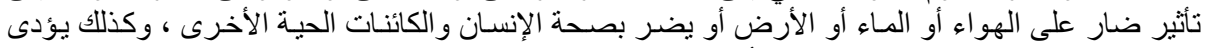

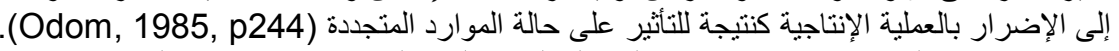

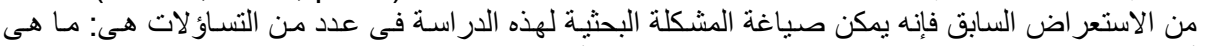

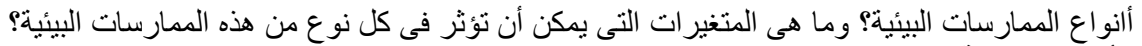

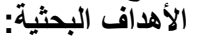

من خلال العرض السابق لمشكلة البحث تحددت أهدافه فيما يلى:

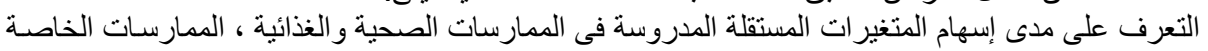

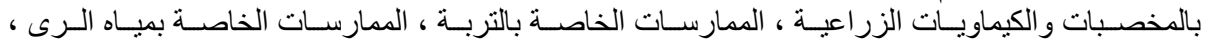

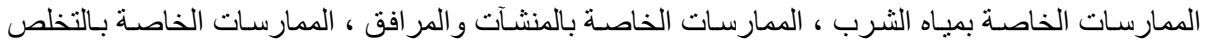

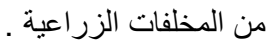

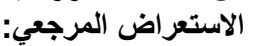

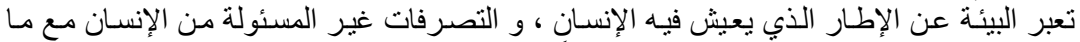

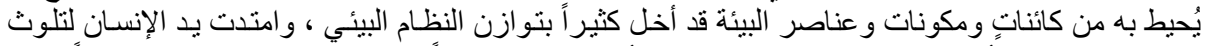

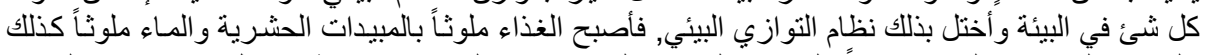

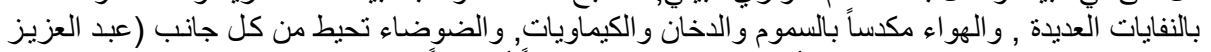

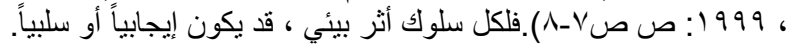

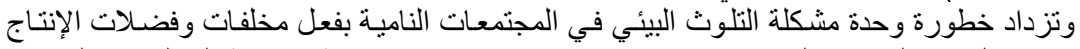

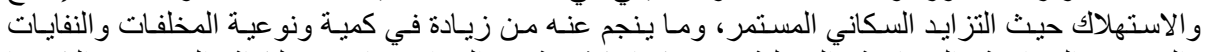

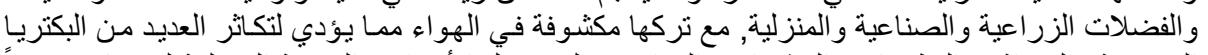

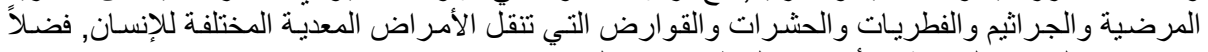

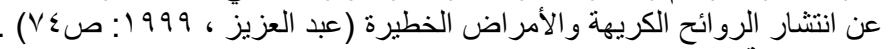

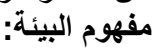

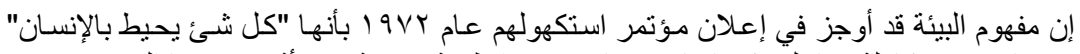

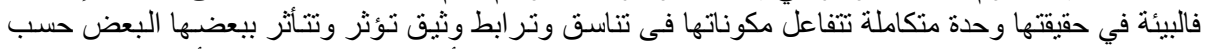

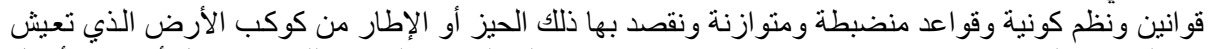

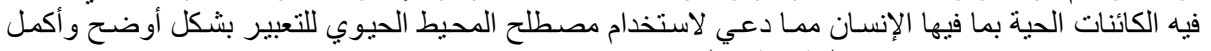

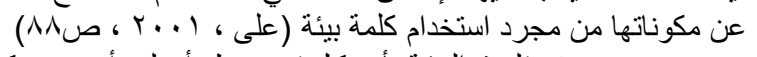

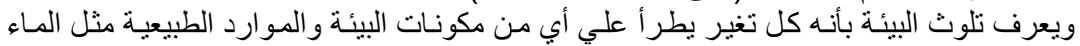

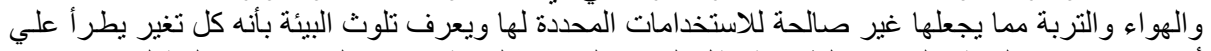

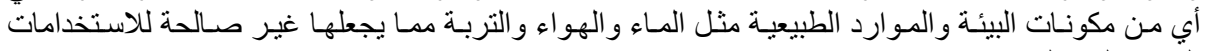

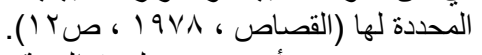

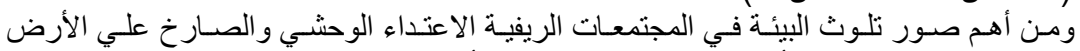

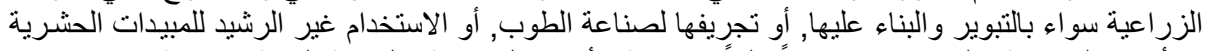

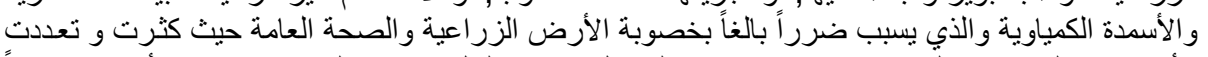

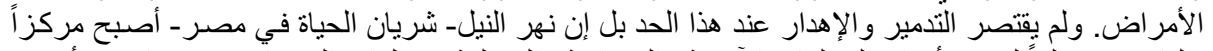

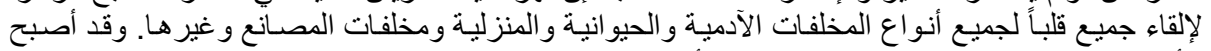

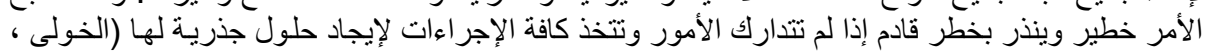

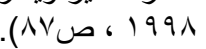

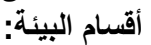

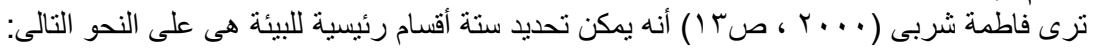




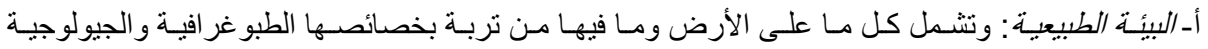

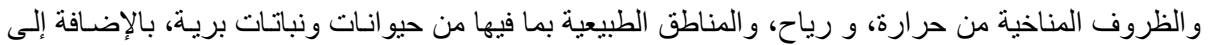

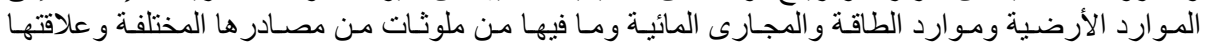

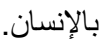

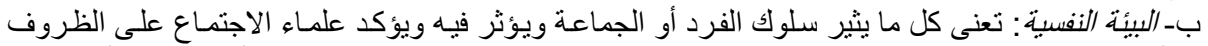

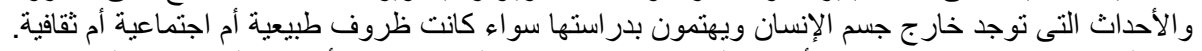

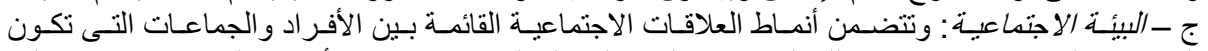

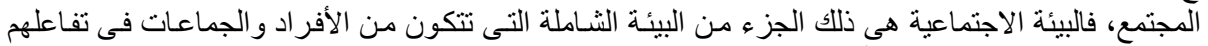

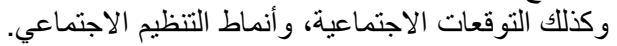

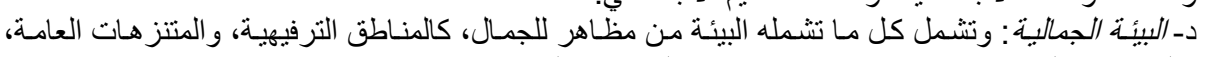

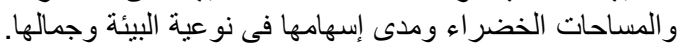

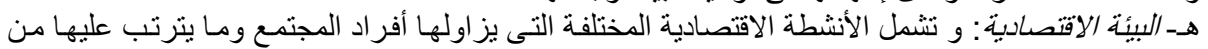

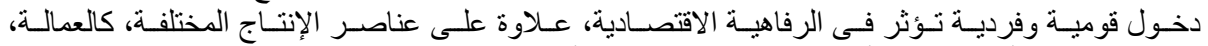

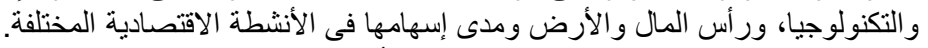

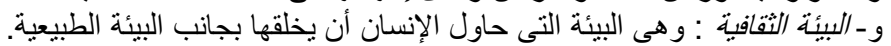

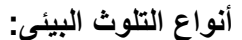

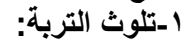

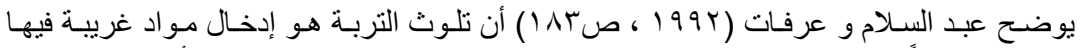

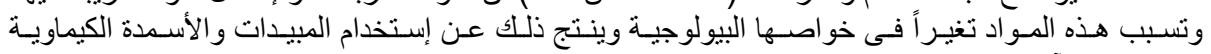

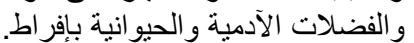

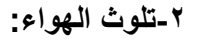

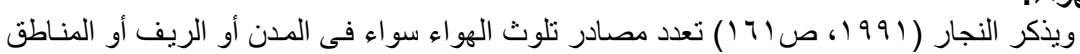

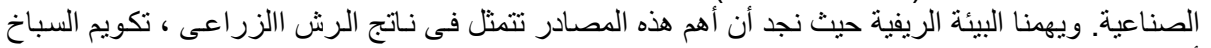

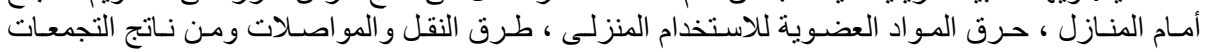

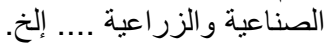
r-تلوث المياه

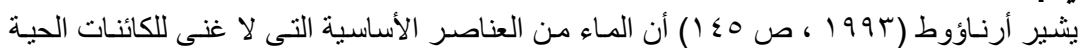

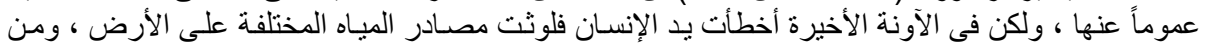

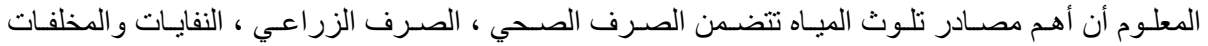

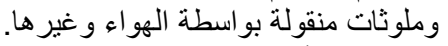

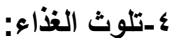

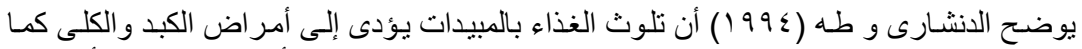

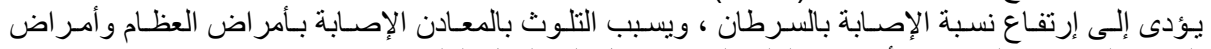

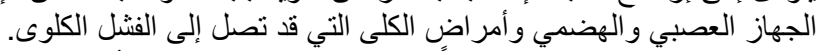

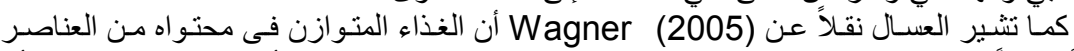

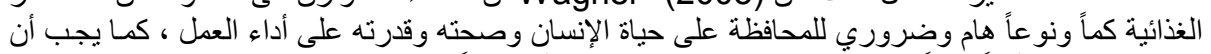

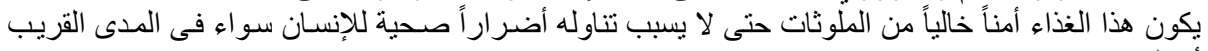
أو البعيد.

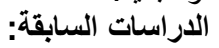

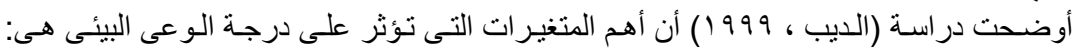

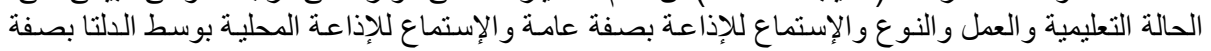

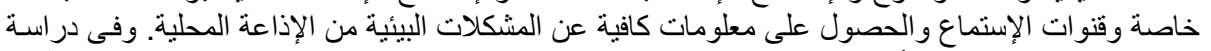

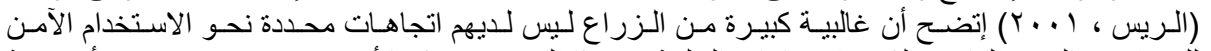

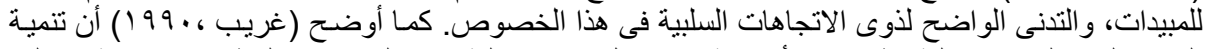

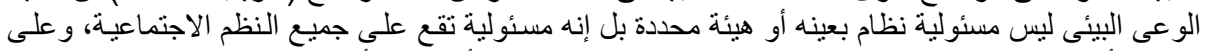

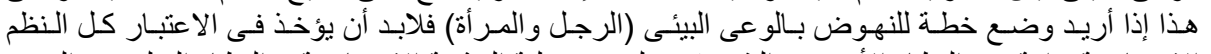

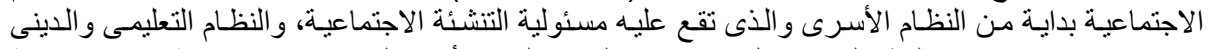

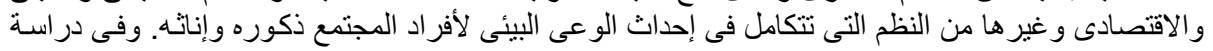


Attia, Amany A. N. E.

أخرى لـ (ريحان و آخرون ، بو 99 1) إتضح أن سلوك الريفيين تجاه البيئة يتصف بعدم وجود الرشد وذلك لها

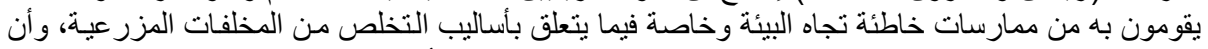

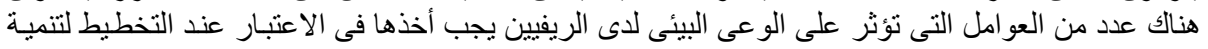

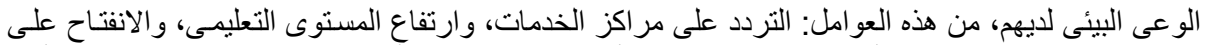

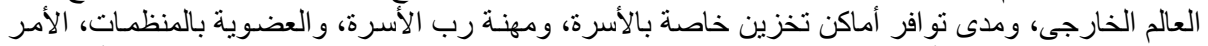

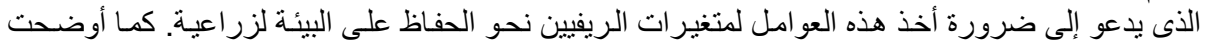

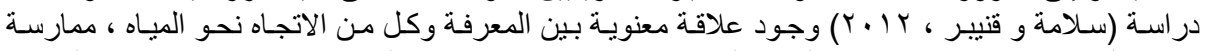

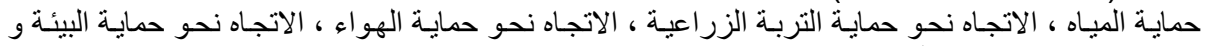

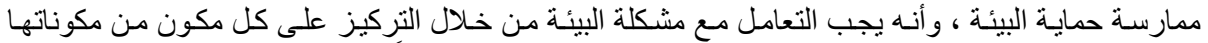

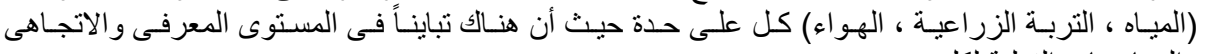

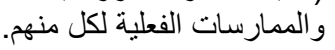
من الاستعراض السابق يتبين أن هناك عدة أنواع للممارسات البيئية هى:

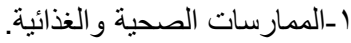

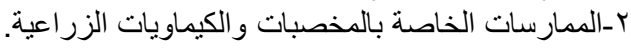

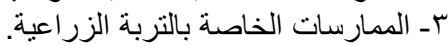

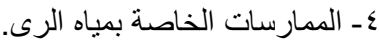

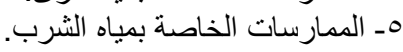

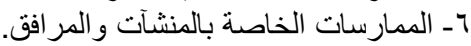

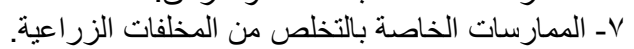

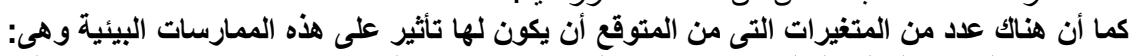

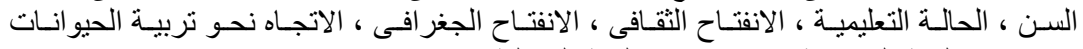

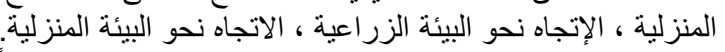
وفى الجزء التالي سوف يتم قياس تلك المتغير التئن تمهيداً لاختبار ها واستطلاع نتائجها.

ولتحقيق الأهداف تم صياغة الفروض البحثية التالية:

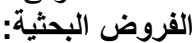

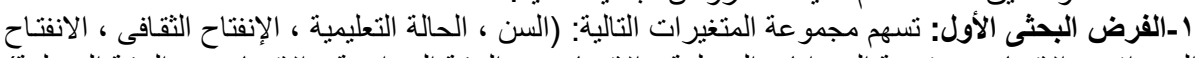

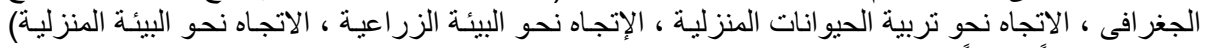

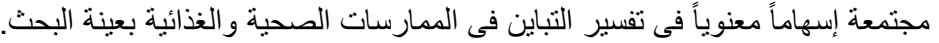

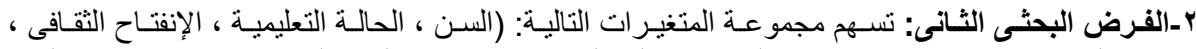

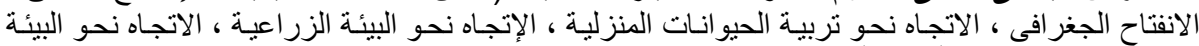

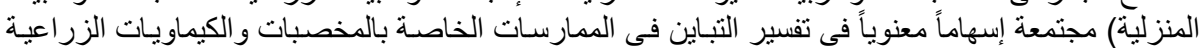

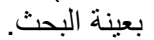

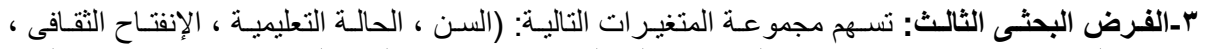

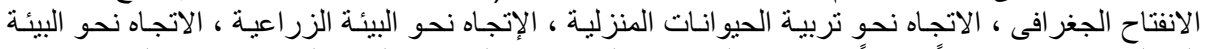

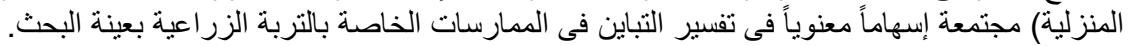

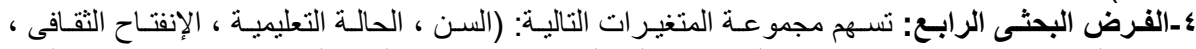

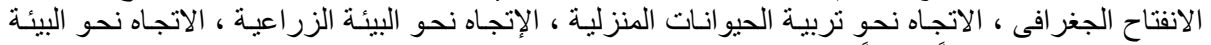

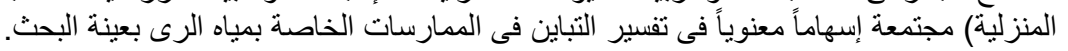

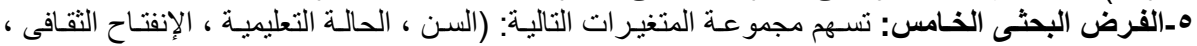

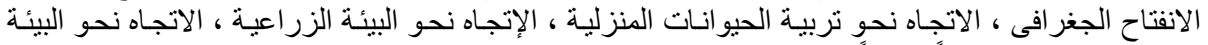

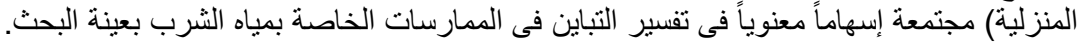

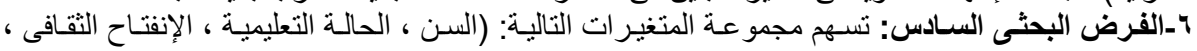

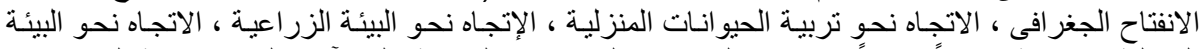

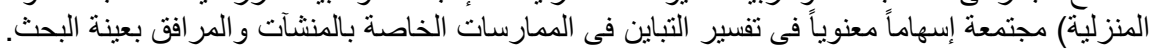

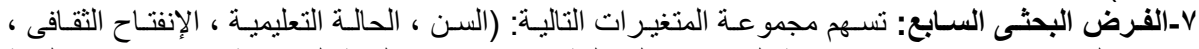

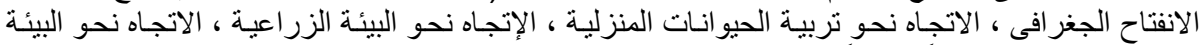

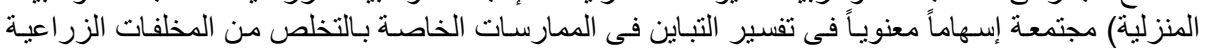




\section{الأسلوب البحثى:}

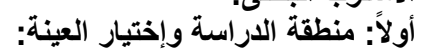

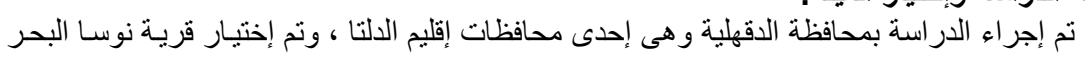

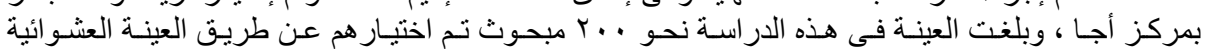

المنتظمة.

ثانياً: أسناليب جمع وتحليل البيانات:

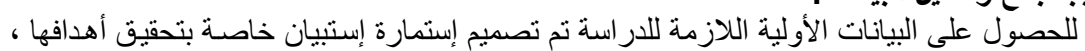

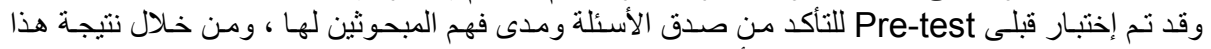

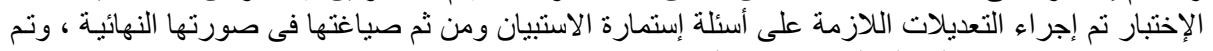

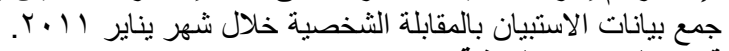
قياس المتغيرات البحثية:

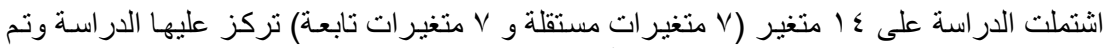
قياس هذه المتغيرات البحثية من استمارة الاستبيان كالغير الآتى:

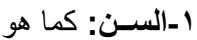

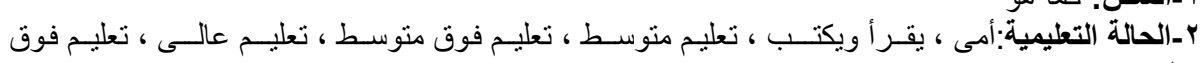

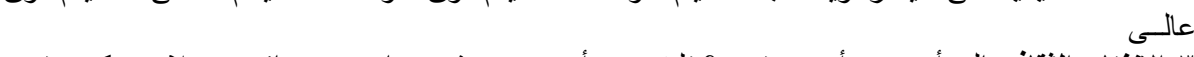
بـالانفتاح الثقافى:إلى أى مدى أنت مهتم بـ؟ تليفزيون أرضى ، دش ، راديو ، جرائد ومجلات ، كمبيوتر ،

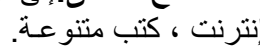

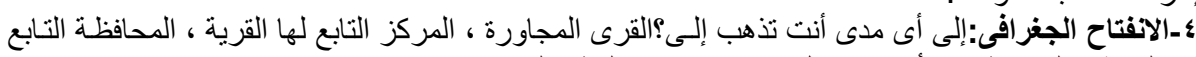

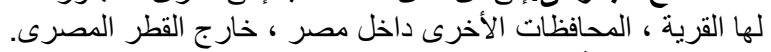

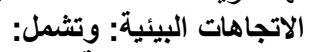

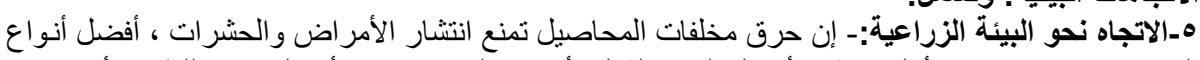

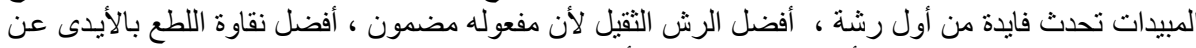

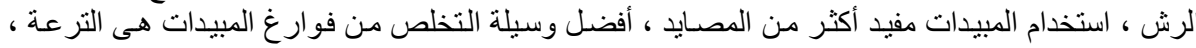

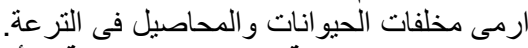

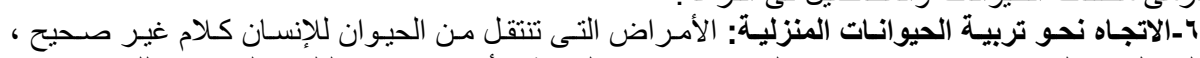

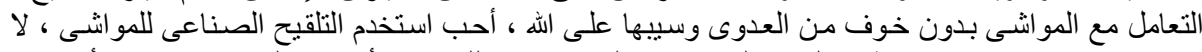

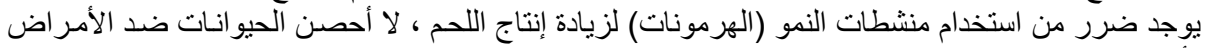

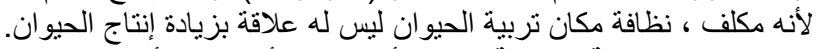

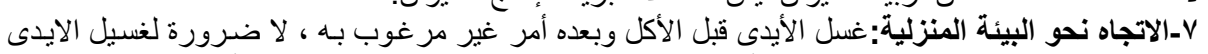

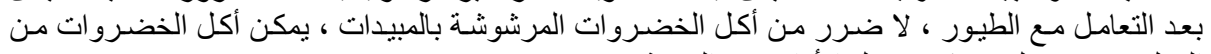

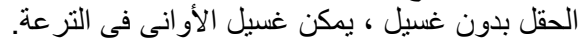

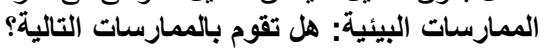

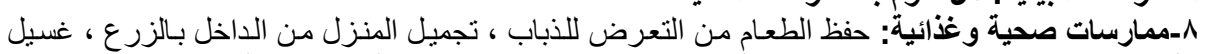

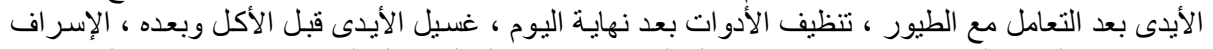

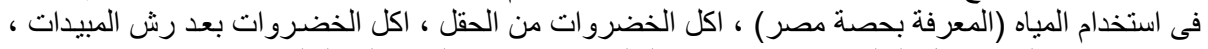

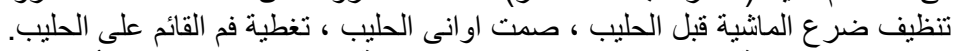

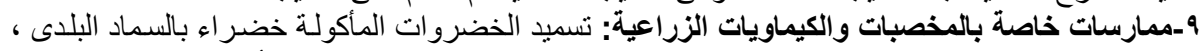

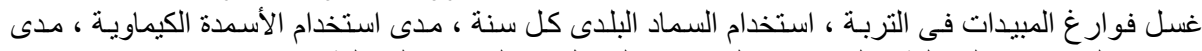

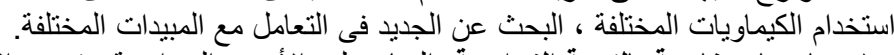

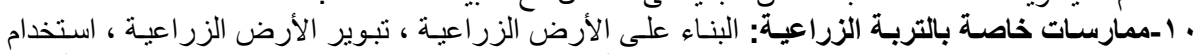

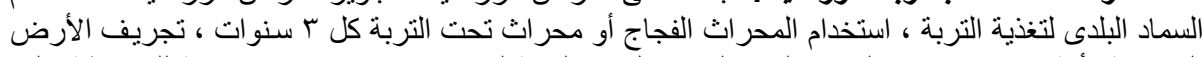

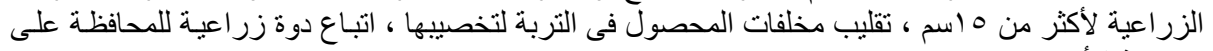
خصوبة الأرض الاكن

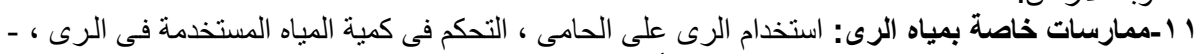

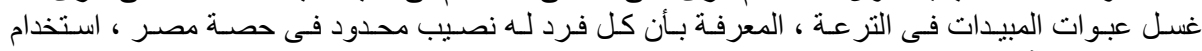

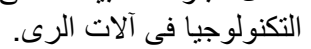


Attia, Amany A. N. E.

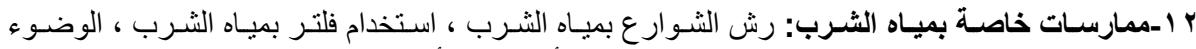

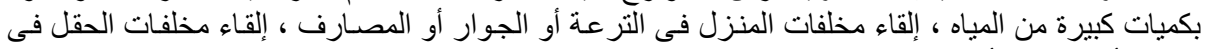

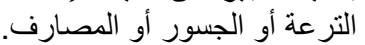

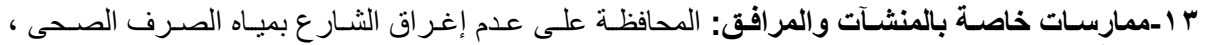

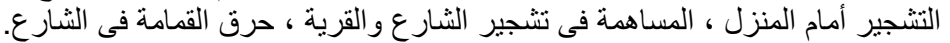

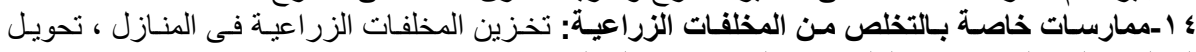

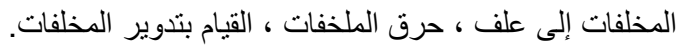

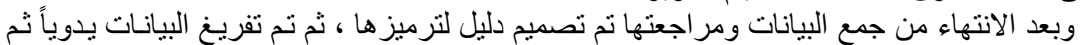

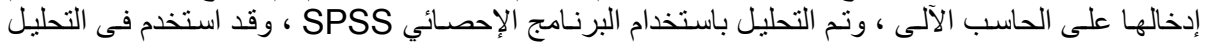
الإحصائي للبيانات أسلوب تحليل الانحدار الخطى التدريجى الصناعد.

\section{النتائج ومناقثتها}

اــأهم المتغيرات المحدة للممارسات الصحية والغذائية:

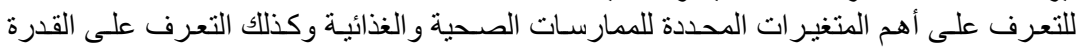

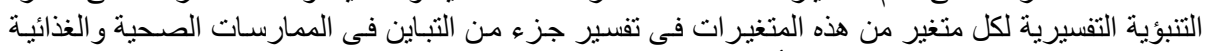

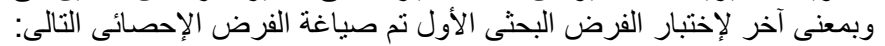

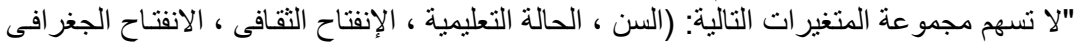

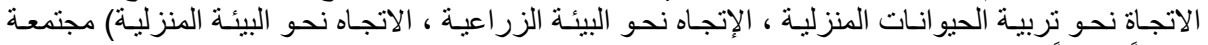

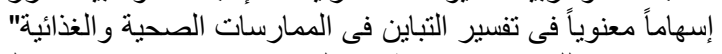

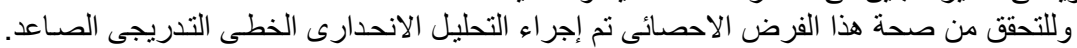

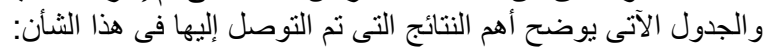

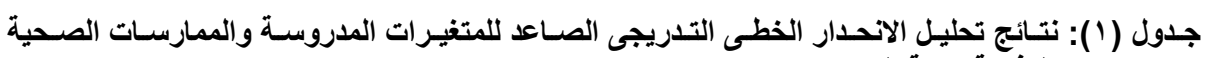

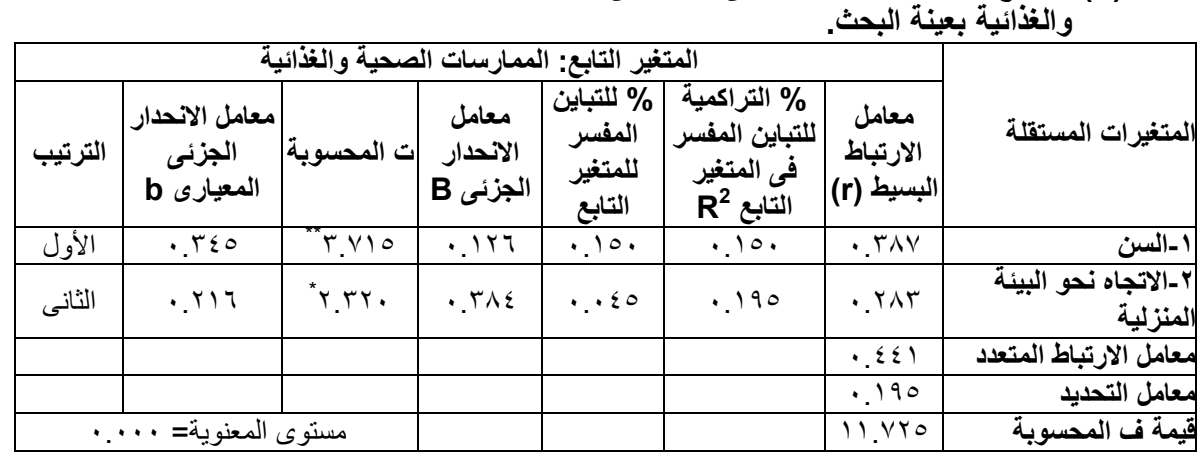

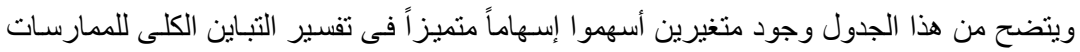

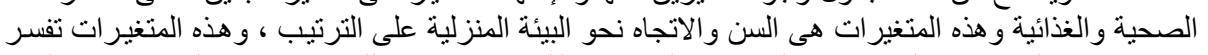

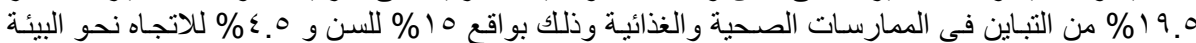
المنزلية.

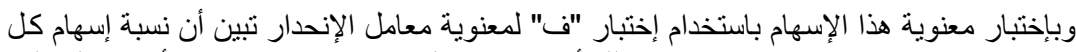

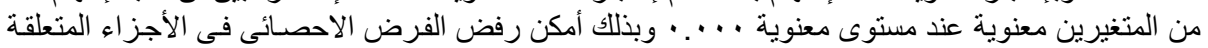

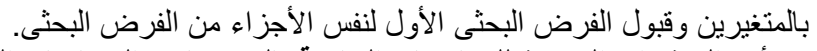

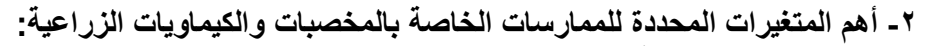

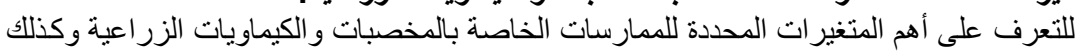

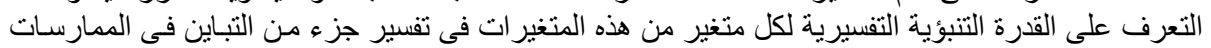

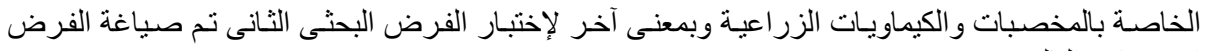
الإحصائى التالى: 


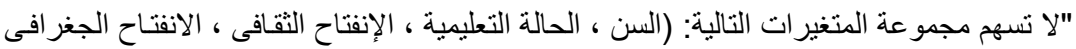

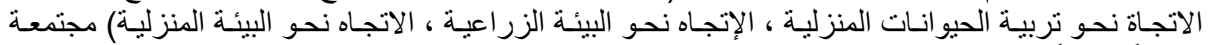

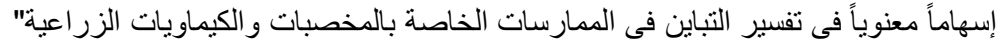

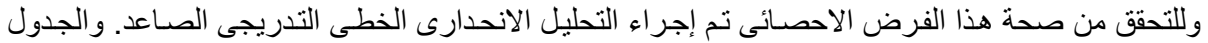
الآتى يوضح أهم النتائج التى تم التوصل الإحنى إليها فى هذا الثنأن:

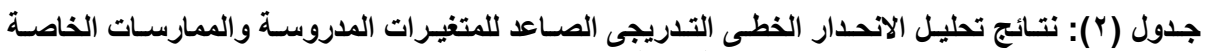

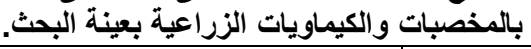

\begin{tabular}{|c|c|c|c|c|c|c|c|}
\hline \multicolumn{7}{|c|}{ المتغير التابع: الممارسات الخاصة بالمخصبات والكيماويات الزراعية } & \multirow[b]{2}{*}{ | المتغيرات المستقلة } \\
\hline 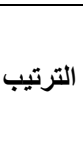 & 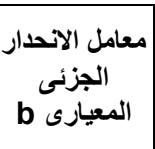 & ت ت المحسوبة & الانحدار & اللمفسر اللتباين & 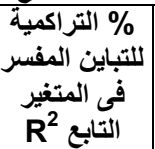 & البسيط الارتباط & \\
\hline 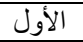 & $\cdot . r 07$ & $* * \varepsilon .71$ & $1.4+q$ & 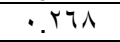 & 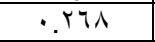 & $.01 \mathrm{~V}$ & | -الحالة التعليمية \\
\hline الثانى & $\cdot r$ r & $*$ r. .01. & $\cdot .44$ & $\because \cdot 14$ & or & $\therefore \varepsilon \vee \varepsilon$ & الحيوالاتات المنزلية تربية \\
\hline \multirow[t]{3}{*}{ 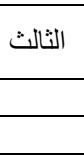 } & 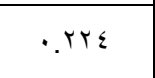 & * Y.orq & $\cdot . \varepsilon \cdot 1$ & $\because \varepsilon$. & $\cdot$. & $\cdot . \leqslant$. & |المنزلاتجاه نحو البيئة \\
\hline & & & & & & $\cdot . T Y V$ & 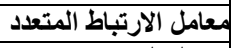 \\
\hline & & & & & &. . $9 \varepsilon$ & معامل التحديا \\
\hline \multicolumn{3}{|c|}{ مستوى المعنوية= =..... } & & & & $4 . . \times 79$ & قيمة ف المحسوبة \\
\hline
\end{tabular}

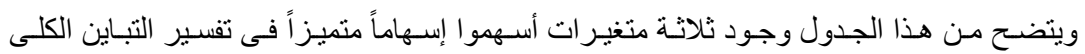

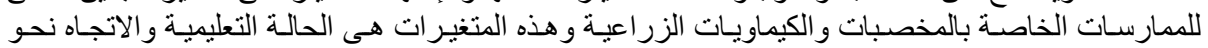

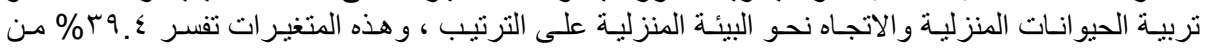

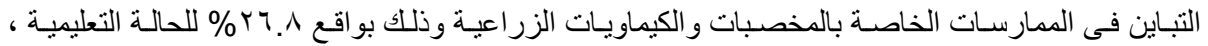

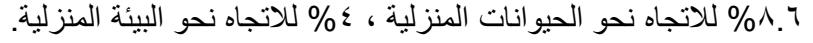

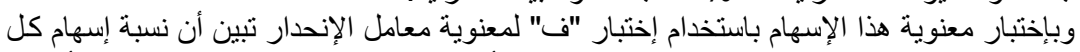

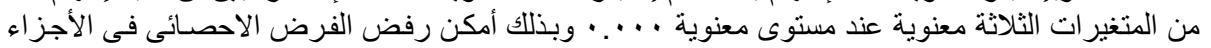

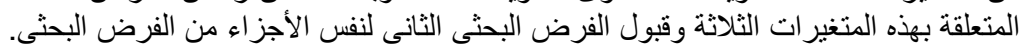

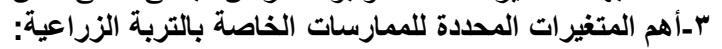

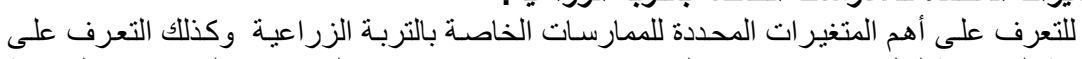

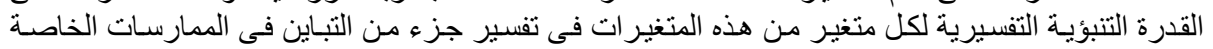

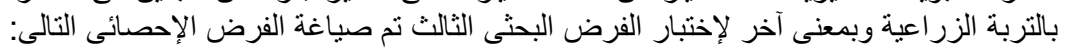

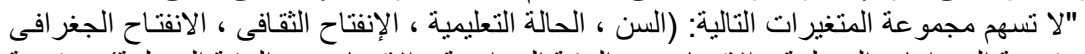

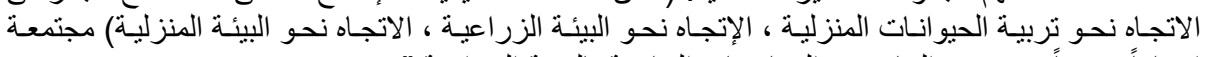

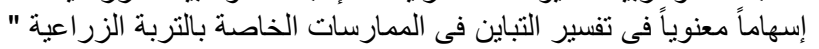

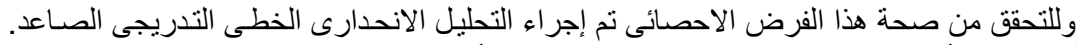

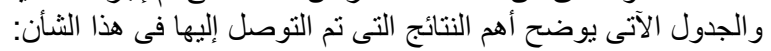

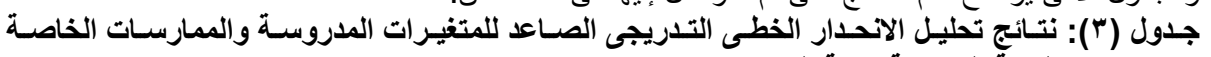

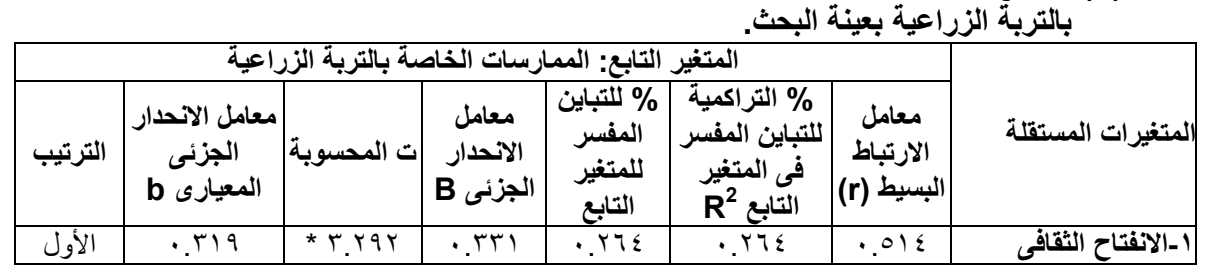


Attia, Amany A. N. E.

\begin{tabular}{|c|c|c|c|c|c|c|c|}
\hline الثنانى & $\cdot .100$ & * Y.VO. & $\because .90$ & $\because .0 \leqslant$ & $\cdot . r 1 \Lambda$ & $\cdot \varepsilon \leqslant V$ & |r-السن \\
\hline الثالث & $\cdot r 10$ & $* r . \leqslant V I$ & . & 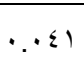 &.$r 09$ & •rV & |المنزلاتجاه نحو البيئة \\
\hline & & & & & &. .099 & بامل الارتباط المتعدد \\
\hline & & & & & & $\therefore . r 09$ & معامل التحديد \\
\hline \multicolumn{3}{|c|}{ مستوى المعنوية= = .... } & & & & $1 V .947$ & قيمة ف المحسوبة \\
\hline
\end{tabular}

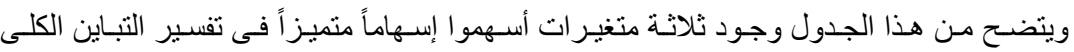

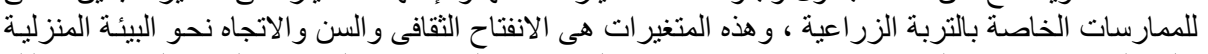

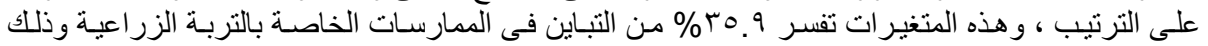

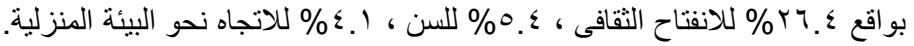

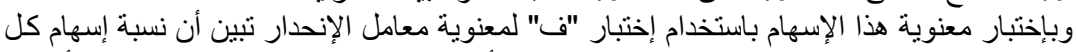

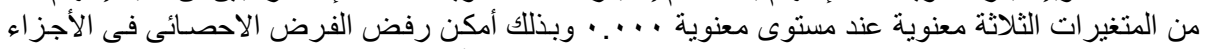

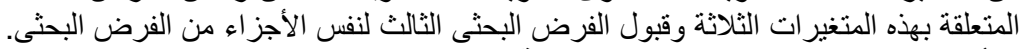

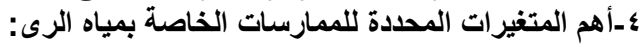

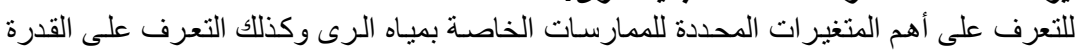

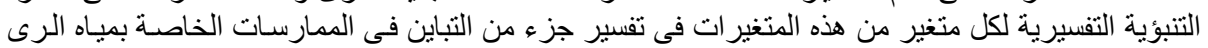

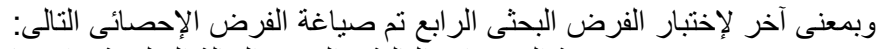

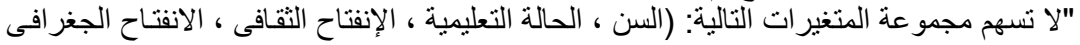

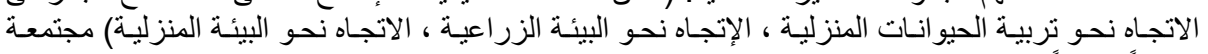

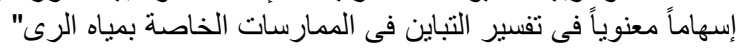

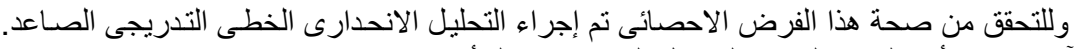
و الجدول الآتى يوضح أهم النتائج التى نم التوصل إليها فى هذا الثنان:

جدول ( ) : نتائج تحليل الانحدار الخطى التدريجى الصـاعد للمتغيرات المدروسـة والممارسـات الخاصـة بمياه

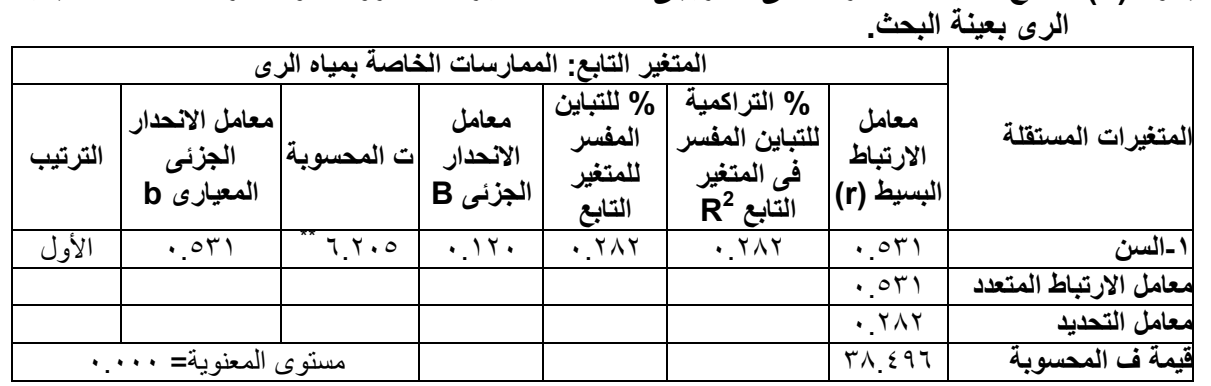

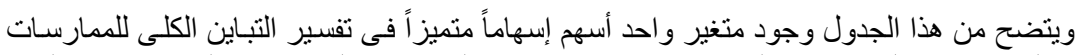

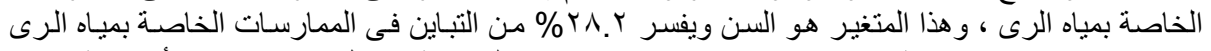

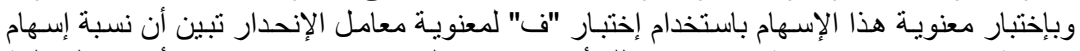

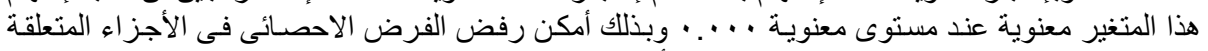

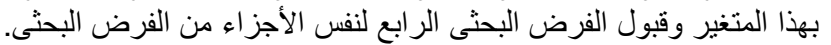

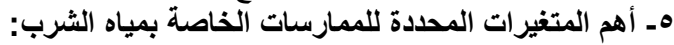

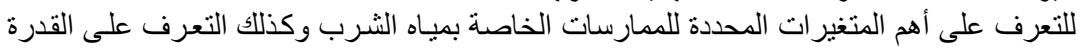

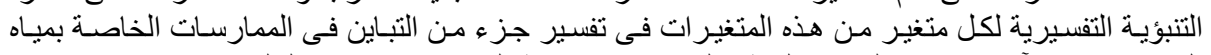

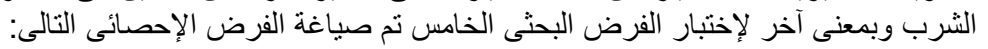

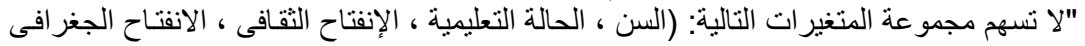

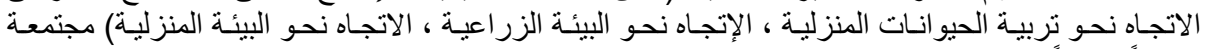

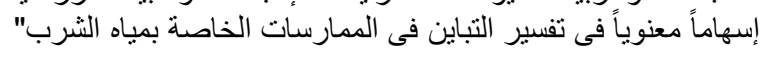




$$
\begin{aligned}
& \text { وللتحقق من صحة هذا الفرض الاحصائى تم إجر اء التحليل الانحدارى الخطى التدريجى الصـاعد. }
\end{aligned}
$$

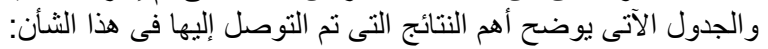

جدول (•): نتائج تعليل الانحار الخطى التدريجى الصـاعد للمتغيرات المدروسـة والممارسـات الخاصة بمياه

\begin{tabular}{|c|c|c|c|c|c|c|c|}
\hline \multicolumn{8}{|c|}{ الثرب بعينة البحث. } \\
\hline \multicolumn{7}{|c|}{ المتغير التابع: الممارسات الخاصة بمياه الشرب } & \multirow[b]{2}{*}{ المتغيرات المستقلة } \\
\hline الترتيب & $\begin{array}{c}\text { الجعلئسى الاتحدار } \\
\text { b المعيارى }\end{array}$ & 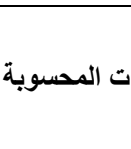 & الانحدار & اللمفسر اللتباين & 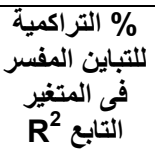 & البسيط البتاط & \\
\hline الأول & $\cdot \varepsilon \cdot r$ & $* * \varepsilon . Y \vee O$ & $.91 \pi$ &. YTY & $\cdot$. Yru & $\cdot . \leqslant \wedge \uparrow$ & |-الحالة التعليمية \\
\hline \multirow[t]{3}{*}{ 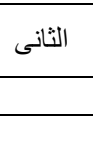 } & $\cdot r \cdot \Lambda$ & *Y.Y.o & $\cdot r \cdot 9$ & $\because+4$ & $\cdot$ TYY & $\cdot .471$ & |الحيوالاتجات المنزلية تربية \\
\hline & & & & & &. OrY & معامل الارتباط المتعدد \\
\hline & & & & & & . TVY & معامل التحديد \\
\hline \multicolumn{3}{|c|}{ مستوى المعنوية= . . ... } & & & & $1 \Lambda .1 \leqslant V$ & قيمة ف المحسوبة \\
\hline
\end{tabular}

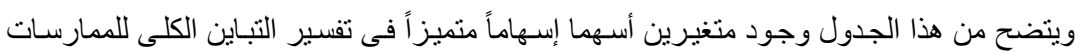

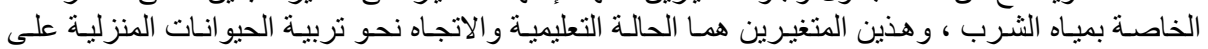

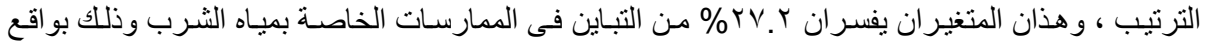

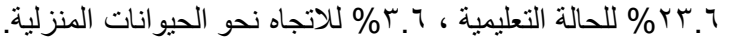

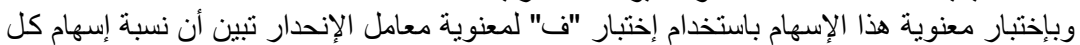

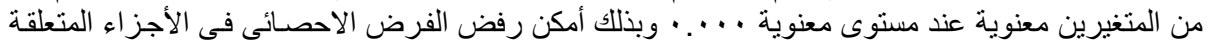

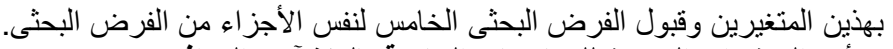

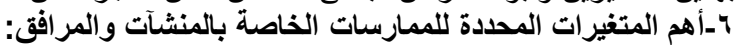

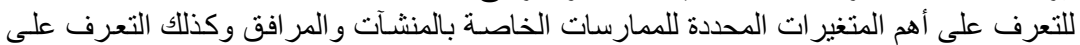

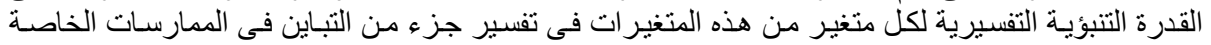

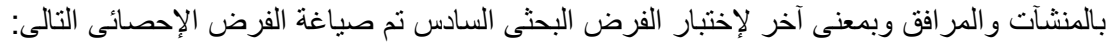

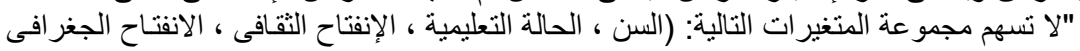

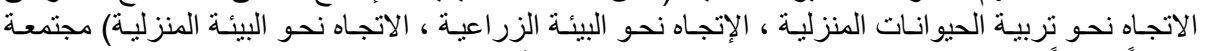

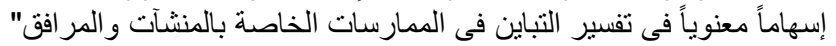

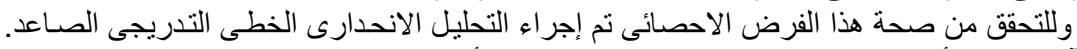

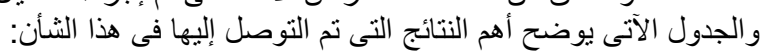

جدول (") : نتـائج تحليـل الاتحـدار الخطى التـريجى الصـاعد للمتغيـرات المدروسـة والممارسـات الخاصـة بالمنشآت والمر افق بعينة البحث.

\begin{tabular}{|c|c|c|c|c|c|c|c|}
\hline \multicolumn{7}{|c|}{ المتغير التابع: الممارسات الخاصة بالمنشآت والمرافق } & \multirow[b]{2}{*}{ لمتغيرات المستقلة } \\
\hline الترتيب & 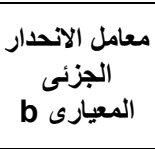 & |ت المحسوبة & الإنحدار & \% اللمتفربزين & للتباين المفسر التمية & |البسيط البتاط & \\
\hline الأول & $\cdot Y V T$ & ${ }^{*} Y . \wedge \leqslant \varepsilon$ & - rro & $\because \cdot \vee 4$ & $\because \cdot V 4$ & $\because Y \vee 4$ & | الالاتجاه نحو تربية \\
\hline & & & & & & - YVT & معامل الارتباط المتعدد \\
\hline & & & & & & $\because .87$ & معامل التحديد \\
\hline
\end{tabular}


Attia, Amany A. N. E.

مستوى المعنوية= 0. م

$\wedge .91$

قيمة ف المحسوبة

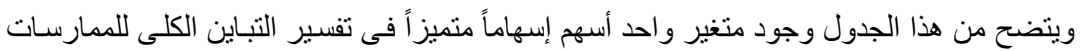

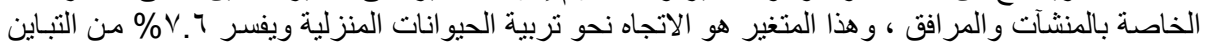

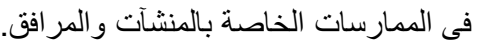

وبإختبار معنويـة هذا الإسـهام باستخدام إختبـار "فـ" لمعنويـة معامل الإنحدار تبـين أن نسبة إسـهام

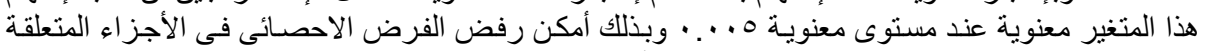

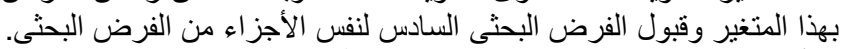

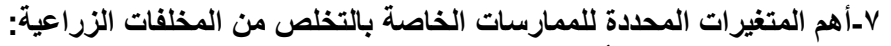

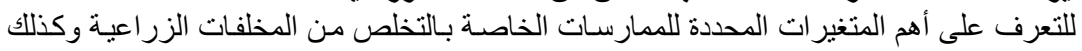

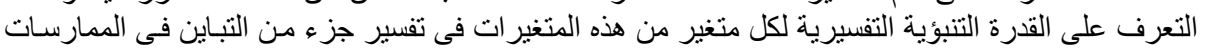

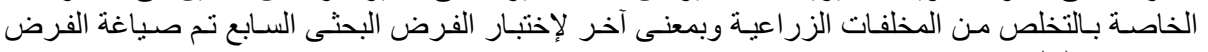

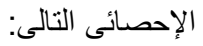

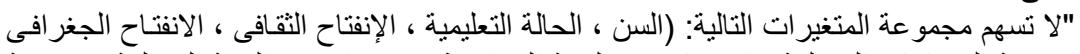

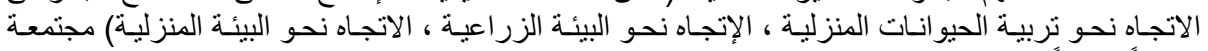

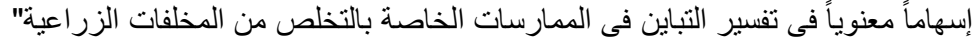

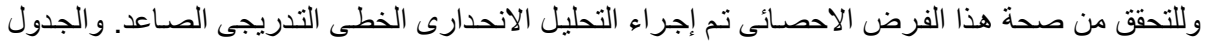

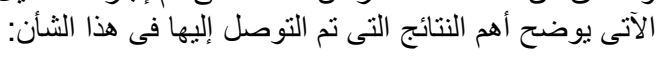

جدول (V): نتـائج تحليـل الانحـدار الخطى التـدريجى الصـاعد للمتغيـرات المدروسـة والممارسـات الخاصـة بالتخلص من المخلفات الزراعية بعينة البحث.

\begin{tabular}{|c|c|c|c|c|c|c|c|}
\hline \multicolumn{7}{|c|}{ المتغير التابع: الممارسات الخاصة بالتخلص من المخلفات الزراعية } & \multirow[b]{2}{*}{ | المتغيرات المستقلة } \\
\hline الترتيب & معامل الانحدار & ت المحسوبة & الانحدار & اللمفتبر اللتبرين & 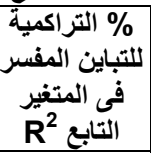 & 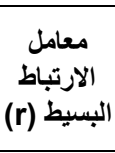 & \\
\hline الأول & $\because \varepsilon \wedge \vee$ & $* *\rceil .0$. &.$r$ r &.$r 0 \wedge$ &.$r 01$ & .091 & | -الانفتاح الثقافى \\
\hline \multirow[t]{3}{*}{ الثانى } & • & **. & •r人. & $\because 9$. & 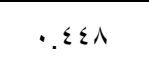 &.$£ 9$. & |لمنزلية ـالاتجــاه نحــو البيئسـا \\
\hline & & & & & & .779 & 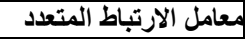 \\
\hline & & & & & & 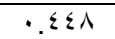 & معامل التحديد \\
\hline \multicolumn{3}{|c|}{ مستوى المعنوية= ..... } & & & & rq. rᄉ & قيمة ف المحسوبة \\
\hline
\end{tabular}

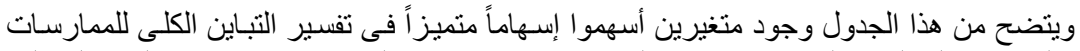

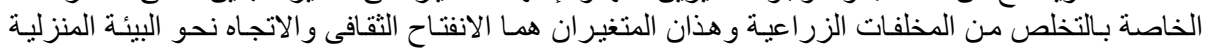

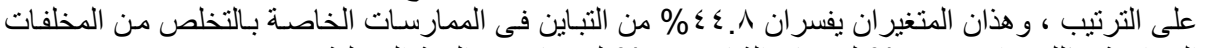

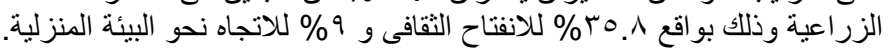

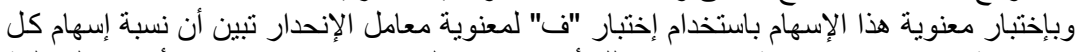

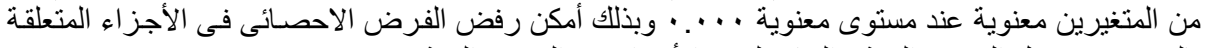

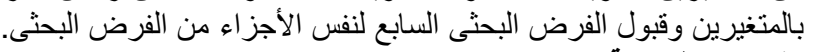
مقترحات الدراسة: بعد إستعر اض الاطلةر النظرى للار اسة وما توصلت إليه من نتائج فإنه يمكن صياغة عدة مقترحات

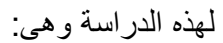

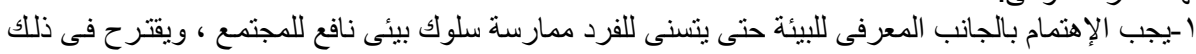

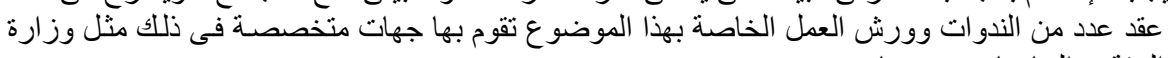

البيئة - الجامعات و غدذ من لندات 


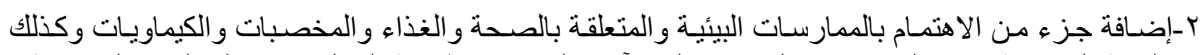

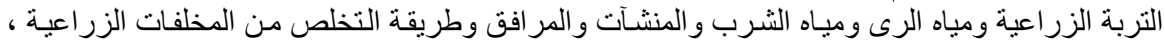

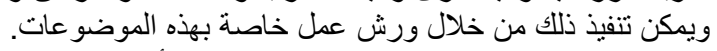

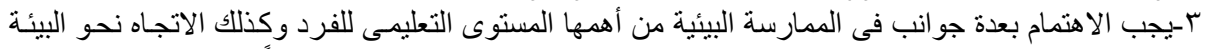

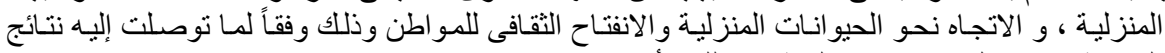

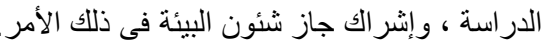

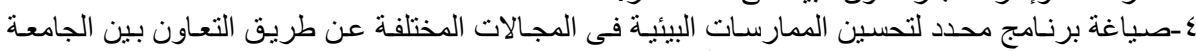

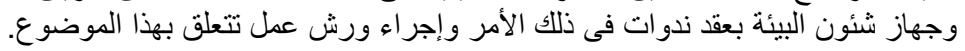

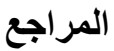

أحمد عبد الوهاب عبد الجواد (دكتور)، التشريعات البيئية، سلسلة دائرة المعارف البيئية، الدار العربيـة للنشر

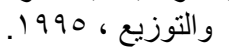

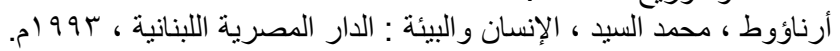

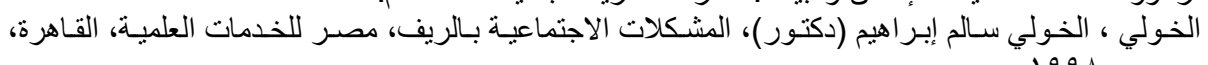
.1991

الدنشارى ، عز الدين و طه ، صـادق أحمد: سموم البيئة "أخطار تلوث الهواء و والمـاء و الغذاء" ، دار المريخ

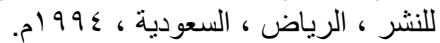

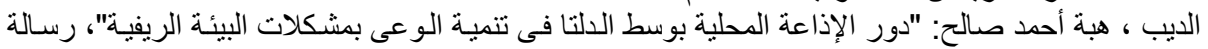

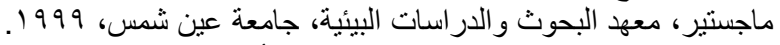

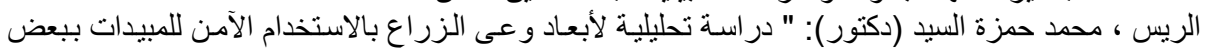

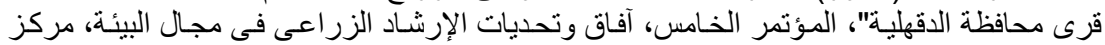

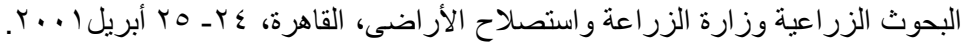

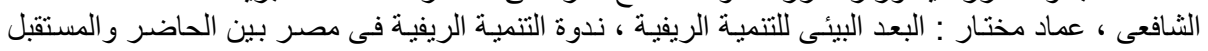

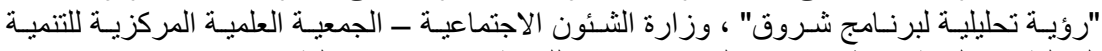

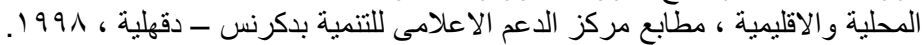

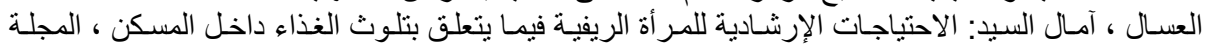

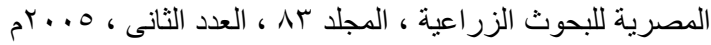

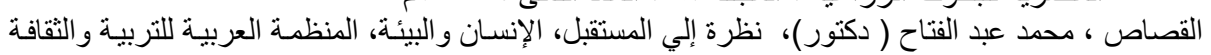

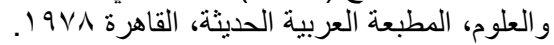

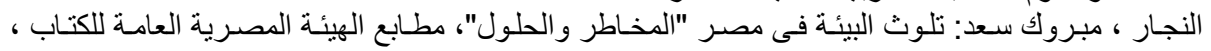
.

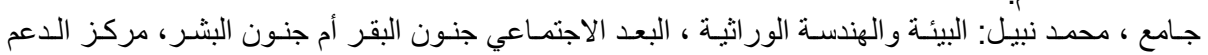

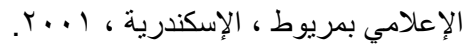

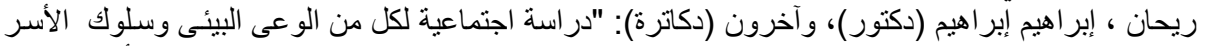

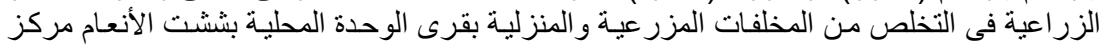

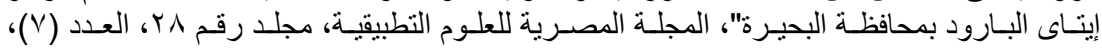
.1994

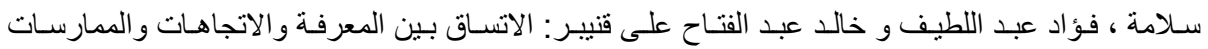

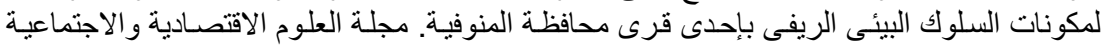

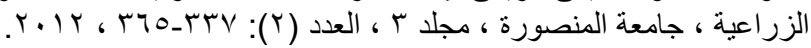

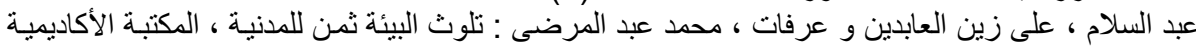

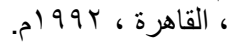

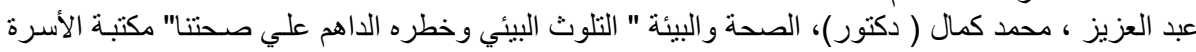

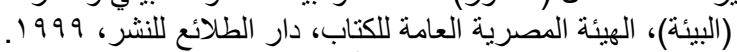

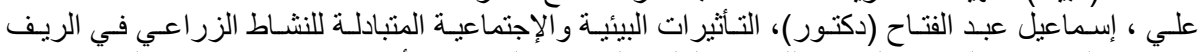

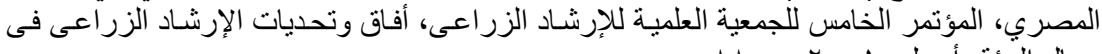

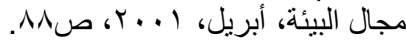


Attia, Amany A. N. E.

$$
\begin{aligned}
& \text { غريب عبد السميع غريب: "تصور مقترح لدور النظم الاجتماعية فى تتمية الوعى البيئى"، رسالة ماجستير، }
\end{aligned}
$$

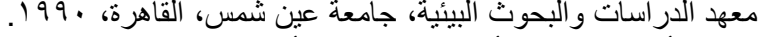

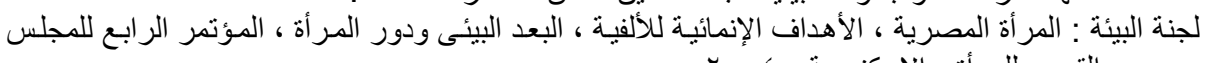

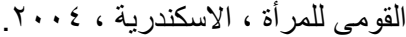

Odom, P., Ecology the link between the natural and the social sciences. Holt Rinehart and Winston, New York, U.S.A., 1985

\section{AN ANALYTICAL STUDY OF THE RELATIONSHIP BETWEEN SOME SOCIAL VARIABLES AND ENVIRONMENTAL PRACTICES:"A FIELD STUDY IN VILLAGE OF DAKAHLIA GOVERNORATE" \\ Attia, Amany A. N. E. \\ Dept. of Agric. Extension and Rural Sociology, Faculty of Agriculture, Mansoura University}

\section{ABSTRACT}

This study aimed to identify the relationship between a set of variables are: age, educational status, cultural cosmopliteness, geographical cosmopliteness, attitudes toward the domestic animals, attitudes toward the agricultural environment, attitudes toward home environment and the environmental practices. A random sample of 200 residents of a village of Nusa Albahr, Aga distrect, Dakahlia Governorate, has been chosen. The data were collected by a questionnaire through a personal interview of the respondents. Statisticaly method of multiple regression analysis was used to test the hypotheses.

The results indicated the following:

1-There were two variables contributed a significant variation in the interpretation of the total variance to the health and nutritional practices, and these variables were the age and attitudes toward home environment, respectively

2-There were three variables contributed to a significant contribution in the interpretation of the total variance of fertilizers and agricultural chemicals practices and these variables were the educational status, attitudes toward domestic animals and attitudes toward home environment, respectively.

3-There were three variables contributed a significant variation in the interpretation of the total agricultural soil practices, and these variables were cultural cosmopliteness, age and attitudes toward home environment, respectively.

4-There was one variable contributed a significant variation in the interpretation of the total variance of the practices of irrigation water, and this variable was the age. 
5-There were two variables contributed a significant variation in the interpretation of the total variance of practice for drinking water, and these two variables were the educational status and attitudes toward domestic animals, respectively.

6 -There was one variable contributed a significant variation in the interpretation of the total variance to the practices of private installations, facilities, and this variable was attitudes toward domestic animals.

7-There were two variables contributed a significant contribution to variation in the interpretation of the total variance of the practices for the disposal of agricultural waste, and these two variables were the cultural cosmopliteness and attitudes toward home environment, respectively.
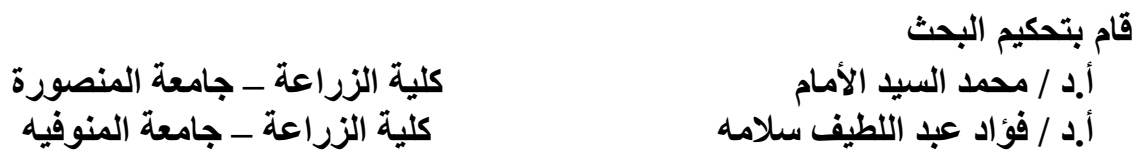